\title{
BONE MINERAL DENSITY AND HORMONAL STATUS IN ADOLESCENT ATHLETIC GIRLS
}

\author{
Rita Gruodytė-RaČIEN $\dot{E}^{1}$, JAAK JÜRIMÄE ${ }^{2}$, MEeli SAAR ${ }^{2}$, \\ Antonio Cicchella ${ }^{3}$, Claudio Stefanelli ${ }^{4}$, \\ Catherine Passariello ${ }^{4}$, Toivo Jürimä ${ }^{2}$ \\ ${ }^{1}$ Department of Health, Physical and Social Education, \\ Lithuanian Academy of Physical Education, Kaunas, Lithuania \\ ${ }^{2}$ Institute of Sport Pedagogy and Coaching Sciences, \\ University of Tartu, Tartu, Estonia \\ ${ }^{3}$ Department of Psychology, Faculty of Exercise and Sport Sciences, \\ University of Bologna, Bologna, Italy \\ ${ }^{4}$ Department of Biochemistry, Faculty of Exercise and Sport Sciences, \\ University of Bologna, Bologna, Italy
}

\begin{abstract}
The aim of this study was to determine the relationships of bone mineral density (BMD) and content (BMC) with selected fasting hormones in adolescents with different exercise training patterns. The participants were female athletes of weight-loaded $(n=23)$ and weight-supported $(n=24)$ sports, and 33 non-athletic girls aged 13-15-years. BMD $\left(\mathrm{g} / \mathrm{cm}^{2}\right)$ and BMC $(\mathrm{g})$ at the femoral neck (FN) and lumbar spine (LS) were measured. Venous blood samples were drawn to determine the concentration of insulin-like growth factor-1 (IGF-1), IGF binding protein-3 (IGFBP-3), estradiol, visfatin, adiponectin, leptin, insulin, and glucose. After adjusting for age, height, and body mass, the relationships of BMD variables with IGF-1, IGF-1/IGFBP-3 molar ratio, estradiol, and leptin levels remained significant only in the weight-loaded sport group $(\mathrm{r}=0.41-0.60$; $\mathrm{p}<0.05)$. Adiponectin was inversely correlated to FN and LS BMD and BMC $(\mathrm{r}=-0.47-0.62 ; \mathrm{p}<0.05)$ in weight-supported sport group only, but after adjustments for age, height, and body mass, these associations disappeared. In this study, concentrations of visfatin, a fairly new adipocytokine, were not related to bone parameters in adolescent girls with different training patterns.
\end{abstract}

Keywords: bone health; insulin-like growth factor-1; estradiol; adipocytokines; adolescent female athletes 


\section{INTRODUCTION}

Bone is a unique, metabolically active tissue that undergoes a continuous remodelling throughout its life cycle. A great number of factors influence the accumulation of bone mineral in humans. Some are endogenic, such as heredity, ethnicity, gender, or endocrine status; the others - exogenic, such as nutrition or physical activity $[12,23]$. Bone mineral is substantially accrued throughout childhood and puberty through the concerted influences of growth and systemic hormones [15]. In girls, bone development may be especially promoted by the increase of estrogen and free, biologically active insulinlike growth factor-1 (IGF-1) levels which occurs at the time of menarche and peak bone mineral accrual velocity, corresponding to ages of 11.5-13.5 years [15]. Evidence exists that several adipocytokines may also have a positive influence on bone mineral density (BMD) of the growing skeleton [8]. Visfatin, adiponectin, and leptin, the cytokine-like hormones, are suggested to carry signals from adipose tissue to bone and contribute to the relationship between fat mass and BMD $[10,11,14,27]$.

It is well known that mechanical loading activity on bone is vitally important for skeletal strength and development. Maximizing BMD and bone mineral content (BMC) during the growing years by adopting weight-bearing physical activity in childhood and adolescence may be one of the most effective osteoporosis prevention strategies [7]. Adolescents engaged in weight-bearing sports (such as gymnastics) appear to achieve significantly greater regional and wholebody gains in bone mineral than adolescents involved in weight-supported activities (such as swimming) [9]. The nature of the sport may affect bone mineralization in adolescent athletes due to a relative state of energy deficiency and changes in body fat mass [17]. Evidence suggest that bone health can be compromised if IGF-1 and estrogen levels are low, particularly in those young female athletes who participate in competitive sports where leanness may be emphasised or aesthetically pleasing (i.e. gymnasts or swimmers) [1,29]. Nevertheless, Courteix et al. [5] suggested that physical activity has beneficial effects on bone that may counterbalance such negative factors of bone health such as low fat mass and insufficient blood leptin levels in adolescent females.

The possible synergism between advancing pubertal status and loading induced bone gain suggests that a "window of opportunity" for bone response may exist in early puberty [15]. However, little information is available concerning the relationships between bone parameters and fasting hormones, especially different adipocytokines, in adolescent female athletes. The aim of this study was to determine the relationships of BMD and BMC with IGF-1, IGF binding protein-3 (IGFBP-3), estradiol, and selected adipocytokines (visfatin, adiponectin, and leptin) in adolescent girls with different training patterns. 


\section{MATERIALS AND METHODS}

\section{Subjects}

In total, 80 healthy 13-15-year-old girls from different schools and sport clubs in Estonia (Tallinn, Tartu, Pärnu) took part in this cross-sectional study. Before entering the study, volunteers completed simple medical and physical activity questionnaires to provide information such as the onset of the training and weekly hours of participating in sports. All participants were free from past or present diseases known to affect skeletal metabolism. None of the girls used birth control or medications known to affect bone. Girls were also asked not to change their eating habits [13]. The participants comprised three groups: athletes of weight-loaded (rhythmic gymnastics; $\mathrm{n}=23$ ) and weight-supported (swimming; $\mathrm{n}=24$ ) sports, and 33 nonathletic healthy girls (untrained controls). The athletic girls must have participated in their selected sports for at least for the last two years (Table 1). Control group girls only took part in compulsory physical education classes at school (i.e. 45 min twice per week). Each girl and her parent (or legal guardian) received a full written description of the nature of the study and signed an informed consent form before participating. The study was approved by the Medical Ethics Committee of the University of Tartu (Estonia).

\section{Measures}

Body height and sitting height were measured to the nearest $0.1 \mathrm{~cm}$ using the Martin's metal anthropometer. Body mass was measured to the nearest $0.05 \mathrm{~kg}$ using medical scales (A\&D Instruments Ltd, Abingdon, UK). The girls were dressed in light clothing and wearing no shoes. Body height and body mass data were used to calculate body mass index $(\mathrm{BMI})\left(\mathrm{kg} / \mathrm{m}^{2}\right)$. The determination of years from the attainment of peak height velocity (PHV) - an indicator of somatic maturity, reflecting the maximum velocity in statural growth during adolescence - was used to assess physical maturity of the participants [2]. Predicted age at PHV (APHV) and biological maturity age (how many years a girl was from APHV) of the participants was estimated using chronological age, body height, sitting height, and body mass data (the predictive equation may be accessed at http://taurus.usask.ca/growthutility/ using one of the Childhood Growth Utility Programs developed by members of the Saskatchewan Childhood Growth and Development Research Group based in the College of Kinesiology, at the University of Saskatchewan, Saskatoon, Saskatchewan, Canada) [2]. The girls were also asked if they had experienced menarche. The data on the age at menarche and the duration of a single menstrual cycle of the girls was obtained using a simple questionnaire. 
BMD $\left(\mathrm{g} / \mathrm{cm}^{2}\right)$ and BMC (g) at femoral neck (FN) and lumbar spine (L2-L4) (LS) were measured by dual-energy X-ray absorptiometry (DXA) using the DPX-IQ densitometer (Lunar Corporation, Madison, WI, USA) equipped with proprietary software, version 3.6. DXA measurements and results were evaluated by the same examiner. Coefficients of variations (CVs) for BMD and BMC measurements in female adolescents were less than $2 \%$.

Venous blood samples to determine the concentration of IGF-1, IGFBP-3, estradiol, visfatin, adiponectin, leptin, insulin, and glucose were drawn between 07:30 and 08:30 a.m. after an overnight fasting. For those girls who had regular menstruation, the fasting blood samples were drawn in the early follicular phase of the menstrual cycle, i.e. days 5-7 after menstrual bleeding started [13]. The levels of IGF-1, IGFBP-3, estradiol and insulin concentrations were analyzed on Immulite 2000 radioimmunoassay (DPC, Los Angeles, CA, USA). The intra- and inter-assay CVs for IGF-1, IGFBP-3, and estradiol were $<7 \%$. The intra- and inter-assay CVs for insulin were $<5 \%$ and $<12 \%$, respectively, at an insulin concentration of $6.6 \mu \mathrm{IU} / \mathrm{mL}$. The levels of visfatin and adiponectin concentrations were analyzed using ELISA kits (AdipoGen and Mediagnost, Aspenhaustr, Germany). The intra- and inter-assay CVs for visfatin were $<10 \%$ and $<8 \%$, and for adiponectin $-<5 \%$ and $<6 \%$, respectively. For leptin concentration an ELISA sandwich (DRG Instruments GmbH, Marburg, Germany) analysis was used. The intra- and inter-assay $\mathrm{CVs}$ were $<7 \%$ and $<12 \%$, respectively. Glucose concentration was measured with a commercial kit (Boehringer, Mannheim, Germany) that employed the hexokinase/glucose-6-phosphate dehydrogenase method. In addition, the IGF-1/IGFBP-3 molar ratio was calculated as it is suggested to be an indirect indicator of free IGF-1 [22]. The molar ratio was obtained as follows: IGF-1 $(\mathrm{ng} / \mathrm{mL}) \times 0.130 /$ IGFBP-3 $(\mathrm{ng} / \mathrm{mL}) \times 0.036$ [18]. In addition, the insulin resistance index was calculated using homeostasis model assessment (HOMA): fasting insulin $(\mu \mathrm{IU} / \mathrm{mL}) \mathrm{x}$ fasting glucose $(\mathrm{mmol} / \mathrm{L}) / 22.5$ [16]. The greater HOMA values indicate the greater level of insulin resistance.

\section{Statistical analysis}

Standard statistical methods were used to calculate means and standard deviations $( \pm S D)$. Normality of parameters was controlled by one sample Kolmogorov-Smirnov test. Statistical comparisons between the groups were made using analysis of variance (ANOVA) and Tukey post hoc test. Pearson product moment correlation coefficients were computed to evaluate the relationships between bone mineral values and measured blood hormones. Partial correlation analysis was performed to assess these relationships while controlling for age, height, and body mass [26]. The effect of hormonal parameters to the $\mathrm{BMD}$ and $\mathrm{BMC}$ was analysed by stepwise multiple regression analysis. 
Statistical significance was set at $\mathrm{p}<0.05$ and all analyses were performed using SPSS 15.0 package for Windows (Chicago, IL, USA).

\section{RESULTS}

The physical characteristics of adolescent girls with different training patterns are presented in Table 1. Although athletes of weight-supported sport (i.e. swimmers) significantly differed from the athletes of weight-loaded sport (i.e. rhythmic gymnasts) and non-athletic girls in respect to the chronological age and predicted age at PHV, no significant differences were found in biological maturity between the studied groups. FN BMD was significantly greater of girls in weight-loaded sport group compared to weight-supported sport and non-athlete groups. No significant differences were found in BMC values between the studied groups. Girls of the weight-loaded sport group had trained significantly more years than those in the weight-supported sport group $(\mathrm{p}<0.05)$. No significant differences were found in blood biochemical parameters among the athlete and control groups (Table 2).

Table 1. Anthropometric, biological maturation, bone mineral values, and training history in adolescent girls with different training patterns (mean $\pm S D$ )

\begin{tabular}{lccc}
\hline & $\begin{array}{c}\text { W-L athletes } \\
\mathbf{n = 2 3}\end{array}$ & $\begin{array}{c}\text { W-S athletes } \\
\mathbf{n = 2 4}\end{array}$ & $\begin{array}{c}\text { Non-athletes } \\
\mathbf{n}=\mathbf{3 3}\end{array}$ \\
\hline Age $(\mathrm{yrs})$ & $14.3 \pm 1.0$ & $13.7 \pm 1.2^{\S}$ & $14.2 \pm 1.1$ \\
\hline Body height $(\mathrm{cm})$ & $163.8 \pm 6.7$ & $164.2 \pm 6.8$ & $163.3 \pm 6.5$ \\
\hline Body mass $(\mathrm{kg})$ & $52.4 \pm 8.9$ & $55.4 \pm 9.2$ & $55.2 \pm 8.1$ \\
\hline BMl $\left(\mathrm{kg} / \mathrm{m}^{2}\right)$ & $19.4 \pm 2.4$ & $20.5 \pm 2.9$ & $20.6 \pm 2.4$ \\
\hline Predicted APHV $(\mathrm{yrs})$ & $12.4 \pm 0.5$ & $12.0 \pm 0.4^{\S}$ & $12.3 \pm 0.4$ \\
\hline Biological maturity age $(\mathrm{yrs})$ & $1.9 \pm 0.9$ & $1.7 \pm 1.0$ & $1.9 \pm 0.9$ \\
\hline Girls having menses $[\mathrm{n}(\%)]$ & $13(56.5)$ & $13(54.2)$ & $29(87.9)$ \\
\hline Menarcheal age $($ years) & $13.0 \pm 0.7$ & $12.5 \pm 0.8$ & $12.5 \pm 0.8$ \\
\hline BMD femoral neck $\left(\mathrm{g} / \mathrm{cm}^{2}\right)$ & $1.13 \pm 0.15^{\#}$ & $1.01 \pm 0.11$ & $1.01 \pm 0.11$ \\
\hline BMD lumbar spine $\left(\mathrm{g} / \mathrm{cm}^{2}\right)$ & $1.12 \pm 0.11$ & $1.08 \pm 0.13$ & $1.08 \pm 0.13$ \\
\hline BMC femoral neck $(\mathrm{g})$ & $4.9 \pm 0.7$ & $4.6 \pm 0.7$ & $4.7 \pm 0.7$ \\
\hline BMC lumbar spine $(\mathrm{g})$ & $44.5 \pm 8.2$ & $41.6 \pm 9.9$ & $41.4 \pm 7.9$ \\
\hline Years of training & $6.5 \pm 1.8$ & $4.8 \pm 1.5^{\dagger}$ & - \\
\hline Training duration $\left(\mathrm{h} / \mathrm{week}^{2}\right.$ & $9.6 \pm 4.9$ & $9.4 \pm 3.2$ & - \\
\hline
\end{tabular}

Note: W-L - weight-loaded sport; W-S - weight-supported sport; BMI - body mass index; APHV - age at peak height velocity; BMD - bone mineral density; BMC - bone mineral content. "Of the girls that have experienced menarche. §Difference from weight-loaded sport athlete and non-athlete groups; $p<0.05$. "Difference from weight-supported sport athlete and non-athlete groups; $p<0.05$. 'Difference from weight-loaded sport athletes; $p<0.05$. 
Table 2. Blood biochemical parameters in adolescent girls with different training patterns $($ mean $\pm S D)$

\begin{tabular}{lccc}
\hline & $\begin{array}{c}\text { W-L athletes } \\
\mathbf{n = 2 3}\end{array}$ & $\begin{array}{c}\text { W-S athletes } \\
\mathbf{n}=\mathbf{2 4}\end{array}$ & $\begin{array}{c}\text { Non-athletes } \\
\mathbf{n = 3 3}\end{array}$ \\
\hline IGF-1 $(\mu \mathrm{g} / \mathrm{L})$ & $443.2 \pm 104.9$ & $463.7 \pm 138.6$ & $419.2 \pm 144.9$ \\
\hline IGFBP-3 $(\mathrm{mg} / \mathrm{L})$ & $6.0 \pm 0.7$ & $5.9 \pm 0.7$ & $5.8 \pm 0.9$ \\
\hline IGF-1/IGFBP-3 molar ratio & $0.27 \pm 0.06$ & $0.28 \pm 0.07$ & $0.26 \pm 0.07$ \\
\hline Estradiol $(\mathrm{pmol} / \mathrm{L})$ & $67.7 \pm 35.2$ & $108.0 \pm 91.4$ & $103.1 \pm 134.5$ \\
\hline Visfatin $(\mathrm{ng} / \mathrm{mL})$ & $0.92 \pm 0.94$ & $0.77 \pm 0.76$ & $0.66 \pm 0.79$ \\
\hline Adiponectin $(\mu \mathrm{g} / \mathrm{mL})$ & $14.1 \pm 6.0$ & $13.1 \pm 6.2$ & $16.0 \pm 7.0$ \\
\hline Leptin $(\mathrm{ng} / \mathrm{mL})$ & $7.8 \pm 5.5$ & $11.4 \pm 9.5$ & $8.6 \pm 8.0$ \\
\hline Insulin $(\mu / \mathrm{l} / \mathrm{mL})$ & $5.6 \pm 3.2$ & $5.0 \pm 3.5$ & $6.0 \pm 3.5$ \\
\hline Glucose $(\mathrm{mmol} / \mathrm{L})$ & $4.9 \pm 0.3$ & $4.9 \pm 0.4$ & $4.8 \pm 0.3$ \\
\hline HOMA & $1.22 \pm 0.73$ & $1.09 \pm 0.73$ & $1.31 \pm 0.79$ \\
\hline
\end{tabular}

Note: W-L - weight-loaded sport; W-S - weight-supported sport; IGF - 1-insulin-like growth factor-1; IGFBP-3 - IGF-binding protein-3; HOMA - homeostasis model assessment

Significant correlations were found between IGF-1, IGF-1/IGFBP-3 molar ratio and both FN and LS BMD ( $\mathrm{r}=0.39-0.59$; $\mathrm{p}<0.05)$ in weight-loaded sport athletes and controls, but after adjusting for age, body height, and body mass, the relationships remained significant $(\mathrm{r}=0.46-0.52 ; \mathrm{p}<0.05)$ only in the athlete group (Table 3 ). Similar trends were revealed regarding BMC values: the levels of IGF-1 and IGF-1/IGFBP-3 molar ratio were correlated with both FN and LS $\mathrm{BMC}(\mathrm{r}=0.38-0.52 ; \mathrm{p}<0.05)$ in non-athletes' group, but after adjustments were applied these relationships ceased to exist (data not shown). The relationships between IGF-1, IGF-1/IGFBP-3 molar ratio and FN BMC were significant $(\mathrm{r}=0.67-0.77 ; \mathrm{p}<0.05)$ in the weight-loaded sport athlete group even after adjusting for age, body height, and body mass (data not shown). BMD values also correlated to estradiol levels $(r=0.45-0.60 ; \mathrm{p}<0.05)$, but in weight-loaded sport athlete group only. After adjusting for age, body height, and body mass, the associations remained significant $(r=0.53-0.60 ; p<0.05)$. Visfatin concentrations were not correlated with FN nor LS BMD in any group ( $p>0.05)$. Adiponectin was found to be inversely related $(\mathrm{p}<0.05)$ to FN BMD $(\mathrm{r}=-0.48)$ and LS BMD $(r=-0.60)$ in the weight-supported sport athlete group, however these relationships disappeared after controlling for age, body height, and body mass (Table 3 ). Leptin concentrations positively correlated with FN and LS BMD $(r=0.43-0.52 ; \mathrm{p}<0.05)$ in the weight-loaded sport athlete group only, even after adjustment for age, body height, and body mass $(r=0.41-0.63 ; p<0.05)$. Similarly, no correlations were found between visfatin and BMC values in any 
of the studied groups; the inverse correlation of adiponectin with FN and LS BMC $(r=-0.47-0.62 ; \mathrm{p}<0.05)$ in weight-supported group disappeared after controlling for age, body height, and body mass; and leptin concentrations positively correlated with FN BMC $(r=0.56 ; \mathrm{p}<0.01)$ in the weight-loaded sport athlete group only, even after adjustment for age, body height, and body mass (data not shown).

Table 3. Pearson correlation for BMD and hormonal variables in athlete and nonathlete groups. Partial correlation analysis (controlled for age, body height, and body mass) is presented in parenthesis

\begin{tabular}{|c|c|c|c|}
\hline & $\begin{array}{c}\text { W-L athletes } \\
n=23\end{array}$ & $\begin{array}{c}\text { W-S athletes } \\
\mathrm{N}=24\end{array}$ & $\begin{array}{c}\text { Non-athletes } \\
n=33\end{array}$ \\
\hline \multicolumn{4}{|l|}{ BMD femoral neck $\left(\mathrm{g} / \mathrm{cm}^{2}\right)$} \\
\hline IGF-1 ( $\mu \mathrm{g} / \mathrm{L})$ & $0.59^{\star \star}\left(0.52^{\star}\right)$ & NS & $0.54^{\star \star}(\mathrm{NS})$ \\
\hline IGFBP-3 (mg/L) & NS & NS & NS \\
\hline IGF-1/IGFBP-3 molar ratio & $0.52^{\star}\left(0.46^{*}\right)$ & NS & $0.57^{\star \star}(\mathrm{NS})$ \\
\hline Estradiol (pmol/L) & $0.60^{\star *}\left(0.60^{\star *}\right)$ & NS & NS \\
\hline Visfatin (ng/mL) & NS & NS & NS \\
\hline Adiponectin $(\mu \mathrm{g} / \mathrm{mL})$ & NS & $-0.48^{\star \star}(\mathrm{NS})$ & NS \\
\hline Leptin (ng/mL) & $0.43^{*}\left(0.41^{\star}\right)$ & NS & NS \\
\hline \multicolumn{4}{|l|}{ BMD lumbar spine $\left(\mathrm{g} / \mathrm{cm}^{2}\right)$} \\
\hline IGF-1 ( $\mu \mathrm{g} / \mathrm{L})$ & $0.56^{\star \star}\left(0.49^{\star}\right)$ & NS & $0.39^{*}(\mathrm{NS})$ \\
\hline IGFBP-3 (mg/L) & $0.44^{\star}(\mathrm{NS})$ & NS & NS \\
\hline IGF-1/IGFBP-3 molar ratio & $0.44^{*}(\mathrm{NS})$ & NS & $0.44^{*}(\mathrm{NS})$ \\
\hline Estradiol (pmol/L) & $0.45^{\star}\left(0.53^{\star}\right)$ & NS & NS \\
\hline Visfatin (ng/mL) & NS & NS & NS \\
\hline Adiponectin $(\mu \mathrm{g} / \mathrm{mL})$ & NS & $-0.60^{\star \star}(\mathrm{NS})$ & NS \\
\hline Leptin (ng/mL) & $0.52^{\star *}\left(0.49^{\star}\right)$ & NS & NS \\
\hline
\end{tabular}

Note: W-L - weight-loaded sport; W-S - weight-supported sport; BMD - bone mineral density; IGF-1 - insulin-like growth factor-1; IGFBP-3 - IGF-binding protein-3. NS - not significant; Statistically significant, ${ }^{*} p<0.05$; Statistically significant, ${ }^{* *} p<0.01$.

Stepwise multiple regression analysis indicated that IGF-1 and estradiol together explained $42.6 \%\left(\mathrm{R}^{2} \times 100\right)$ of the total variance at FN BMD, and IGF-1 alone $35.4 \%\left(R^{2} \times 100\right)$ of the total variance at FN BMC in weight-loaded sport athlete group (data not shown). 


\section{DISCUSSION}

The results of this study indicate that regular training in high-impact weightbearing sport, such as rhythmic gymnastics, may positively contribute to the bone health of adolescent girls. In this group of athletes, the correlations of FN and LS BMD with IGF-1, estradiol and leptin, as well as FN BMD with IGF-1/IGFBP-3 molar ratio, and FN BMC with IGF-1, IGF-1/IGFBP-3 molar ratio and leptin remained significant even after adjusting for major confounders. Stepwise multiple regression analysis emphasised the association between IGF-1, estradiol and FN BMD as well as IGF-1 and FN BMC in this particular group. Similarly, Snow et al. [25] reported IGF-1/IGFBP-3 molar ratio to be the most robust predictor of FN BMD and suggested that IGF-1 may be a mediator of the muscle-bone relationship in young women with different exercise patterns.

Estradiol plays a significant role in bone formation. In pubertal females, estradiol inhibits bone resorption during growth and acts at higher concentrations to promote bone formation after menarche is reached [26]. Yilmaz et al. [28] found positive correlations between the levels of serum estradiol and BMD (LS and total body) in healthy non-athletic girls aged $10-15$ years. It was observed that the increase in levels of serum estradiol at different pubertal stages in girls is accompanied by an increment in BMD values [28]. Our results suggest that regular weight-bearing physical activity during pubertal growth may positively affect bone mineralization, since estradiol and bone mineral values are interrelated significantly and independently from such major confounders as age, body height and body mass in the weight-loaded sport athlete group.

In female adolescents, Huang et al. [10] found that levels of adiponectin were negatively associated with total body BMD. The same authors reported positive associations between leptin and total body BMD [10]. Similar trends were observed in this study: FN and LS BMD were correlated inversely to adiponectin levels in the weight-supported sport athlete group; while FN and LS BMD had a positive relationship to leptin concentration levels in the weight-loaded sport athlete group. Evidence of the effects of visfatin on bone is scant: visfatin has been found to increase bone mineralization, promote glucose uptake, and downregulate osteocalcin secretion in human osteoblasts [27]. To date, only a few studies aimed to investigate the relationships of visfatin and bone mineral values in humans. Peng et al. [21] found visfatin to be related with hip BMD but not with LS or total body BMD in a population of Chinese men aged 20-80. In contrary, visfatin was not found to be an independent predictor of BMD in a population of post-menopausal Chinese women [30]. Recent investigation of the relationships of visfatin with bone density in middle-aged 
patients with metabolic syndrome revealed plasma visfatin levels to be positively correlated to LS BMD in men, but not women [11]. Although the above mentioned studies involved older populations, to our knowledge the relationships of visfatin with bone mineral values were not studied in pediatrics to date. In our study, no significant correlations were observed between visfatin levels and bone mineral variables in adolescent girls with different training patterns. It may be suggested that visfatin, known to be associated with adiposity and contributing to the relationship between fat mass and bone mineral values, may not play a significant role in bone tissue development in relatively lean healthy adolescent females. In this study, in weight-loaded sport athlete group a trend for lower levels of estradiol and leptin concentration was observed and FN BMD was significantly higher than that of the weight-supported sport athlete and non-athlete groups. This is in consistence to the findings of other studies. Munoz et al. [19] found leptin concentrations to be lower and FN BMD higher in adolescent rhythmic gymnasts when compared to controls. Courteix et al. [5] reported leptin concentrations of rhythmic gymnast to be as low as those observed in anorectic subjects; nevertheless, the BMD and BMC values in gymnasts were greater than in controls, concluding that physical activity counterbalanced the negative effect that low fat mass and leptin deficiency has on bone. It seems that hypoestrogenism and hypoleptinemia may be partly compensated by engaging in frequent high-impact loading $[5,19]$. There was no surprise to find FN BMD to be significantly greater in weight-loaded sport athlete group in this study. It has been shown previously that gymnastics training is beneficial to bone health in children and adolescents $[4,20]$. In a cross-sectional study of prepubescent girls, Scerpella et al. [24] observed a dose-depended relationship between BMD and hours per week of gymnastics activity. Swimming as a non-weight-bearing sport is considered to be associated with lower BMD in athletes [3]. The difference between the groups with regard to the BMD at the spine was not as pronounced as at proximal femur most likely because FN BMD experiences greater mechanical loading during high-impact activities than LS BMD.

There are several shortcomings to this study. The cross-sectional design does not allow us to derive a cause-effect conclusion in this study and the sample size is relatively small. The use of DXA technology provides a static measure of bone density. In this study, bone biochemical markers were not used, but could have provided insights into more acute independent measures of bone status in relation to hormone markers. Our results provide some background information on evaluation of the relationship of IGF-1, estradiol and different adipocytokines with bone mineral variables in adolescent female athletes and untrained controls. 
In summary, after adjustment for major confounders, FN and LS BMD correlated with concentrations of IGF-1, estradiol and leptin, as well as FN BMD with IGF-1/IGFBP-3 molar ratio, and FN BMC with IGF-1, IGF-1/IGFBP-3 molar ratio, and leptin in adolescent female athletes of weightloaded sport only. The concentrations of visfatin, a fairly new adipocytokine, were not related to bone parameters in healthy adolescent girls with different training patterns. The FN BMD was significantly higher in weight-loaded athletes, supporting the benefits of regular weight-bearing physical activity during growth and maturation.

\section{ACKNOWLEDGEMENTS}

This study was supported by Grant TKKSP 0489 from the Estonian Ministry of Education and Research.

\section{REFERENCES}

1. Baxter-Jones ADG, Mundt CA. (2007) The young athlete. In: Armstrong N. (ed). Advances in Sport and Exercise Science Series. Paediatric Exercise Physiology. Elsevier Limited, 299-324

2. Baxter-Jones ADG, Sherar LB. (2007) Growth and maturation. In: Armstrong N (ed). Advances in Sport and Exercise Science Series. Paediatric Exercise Physiology. Elsevier Limited, 1-26

3. Bellew JW, Gehrig L. (2006) A comparison of bone mineral density in adolescent female swimmers, soccer players, and weight lifters. Pediatr Phys Ther, 18: 19-22

4. Courteix D, Jaffre C, Obert P, Benhamou L. (2001) Bone mass and somatic development in young female gymnasts: a longitudinal study. Pediatr Exerc Sci, 13: $422-434$

5. Courteix D, Rieth N, Thomas T, Van Praagh E, Benhamou CL, Collomp K, Lespessailles E, Jaffre C. (2007) Preserved bone health in adolescent elite rhythmic gymnasts despite hypoleptinemia. Horm Res, 68: 20-27

6. Fehling PC, Aleksel L, Clasey J, Rector A, Stillman RJ. (1995) A comparison of bone mineral densities among female athletes in impact loading and active loading sports. Bone 17: 205-210

7. French SA, Fulkerson JA, Story M. (2000) Increasing weight-bearing physical activity and calcium intake for bone mass growth in children and adolescents: a review of intervention trials. Prev Med, 31: 722-731

8. Garnett SP, Högler W, Blades B, Baur LA, Peat J, Lee J, Cowell CT. (2004) Relation between hormones and body composition, including bone, in prepubertal children. Am J Clin Nutr, 80: 966-972

9. Green DA, Naughton GA. (2006) Adaptive skeletal responses to mechanical loading during adolescence. Sports Med, 36: 723-732 
10. Huang KC, Cheng WC, Yen RF, Tsai KS, Tai TY, Yang WS. (2004) Lack of independent relationship between plasma adiponectin, leptin levels and bone density in nondiabetic female adolescents. Clin Endocrinol, 61: 204-208

11. Iacobellis G, Iorio M, Napoli N, Cotesta D, Zinnamosca L, Marinelli C, Petramala L, Minisola S, D’Erasmo E, Letizia C. (2011) Relation of adiponectin, visfatin and bone mineral density in patients with metabolic syndrome. J Endocrinol Invest, 34: e12-e15

12. Javaid MK, Cooper C. (2002) Prenatal and childhood influences on osteoporosis. Best Pract Res Clin Endocrinol Metab, 16: 349-367

13. Jürimäe J, Cicchella A, Jürimäe T, Lätt E, Haljaste K, Purge P, Hamra J, von Duvillard SP. (2007) Regular physical activity influences plasma ghrelin concentration in adolescent girls. Med Sci Sports Exerc, 39: 1736-1741

14. Jürimäe J, Jürimäe T. (2007) Adiponectin is a predictor of bone mineral density in middle-aged premenopausal women. Osteoporos Int, 18: 1253-1259

15. MacKelvie KJ, Khan KM, McKay HA. (2002) Is there a critical period for bone response to weight-bearing exercise in children and adolescents? A systematic review. Br J Sports Med, 36: 250-257

16. Matthews DR, Hosker JP, Rudenski AS, Naylor BA, Treacher DF, Turner RC. (1985) Homeostasis model assessment: insulin resistance and beta-cell function from fasting plasma glucose and insulin concentrations in men. Diabetologia, 28: 412-419

17. Misra M. (2008) Bone density in the adolescent athlete. Rev Endocr Metab Disord, 9: 139-144

18. Morimoto LM, Newcomb PA, White E, Bigler J, Potter JD. (2005) Variation in plasma insulin-like growth factor-1 and insulin-like growth factor binding protein-3: genetic factors. Cancer Epidemiol Biomarkers Prev, 14: 1394-1401

19. Munoz MT, Piedra C, Barrios V, Garrido G, Argente J. (2004) Changes in bone density and bone markers in rhythmic gymnasts and ballet dancers: implications for puberty and leptin levels. Eur J Endocrinol, 151: 491-496

20. Nurmi-Lawton JA, Baxter-Jones AD, Mirwald RL, Bishop JA, Taylor P, Cooper C, New SA. (2004) Evidence of sustained skeletal benefits from impact-loading exercise in young females: A 3-year longitudinal study.J Bone Miner Res, 19: 314-322

21. Peng XD, Xie H, Zhao Q, Wu XP, Sun ZQ Liao EY. (2008) Relationships between serum adiponectin, leptin, resistin, visfatin levels and bone mineral density, and bone biochemical markers in Chinese men. Clin Chim Acta, 387: 31-35

22. Pomerants T, Tillmann V, Jürimae J, Jürimäe T. (2007) The influence of serum ghrelin, IGF axis and testosterone on bone mineral density in boys at different stages of sexual maturity. J Bone Miner Metab, 25: 193-197

23. Rizzoli R, Bianchi ML, Garabedian M, McKay HA, Moreno LA. (2010) Maximizing bone mineral mass gain during growth for the prevention of fractures in the adolescents and the elderly. Bone 46: 294-305

24. Scerpella TA, Davenport M, Morganti CM, Kanaley JA, Johnson LM. (2003) Dose related association of impact activity and bone mineral density in pre-pubertal girls. Calcif Tissue Int, 72: 24-31 
25. Snow CM, Rosen CJ, Robinson TL. (2000) Serum IGF-I is higher in gymnasts than runners and predicts bone and lean mass. Med Sci Sports Exerc, 32: 1902-1907

26. Wang Q, Nicholson PHF, Suuriniemi M, Lyytikäinen A, Helkala E, Alen M, Suominen H, Cheng S. (2004) Relationship of sex hormones to bone geometric properties and mineral density in early pubertal girls. J Clin Endocrinol Metab, 89: $1698-1703$

27. Xie H, Tang SY, Luo XH, Huang J, Cui RR, Yuan LQ, Zhou HD, Wu XP, Liao EY. (2007) Insulin-like effects of visfatin on human osteoblasts. Calcif Tissue Int, 80: 201-210

28. Yilmaz D, Ersoy B, Bilgin E, Gumuser G, Onur E, Pinar ED. (2005) Bone mineral density in girls and boys at different pubertal stages: relation with gonadal steroids, bone formation markers, and growth parameters. J Bone Miner Metab, 23: 476-482

29. Zanker C, Hind K. (2007) The effect of energy balance on endocrine function and bone health in youth. In: Daly R., Petit M. (eds). Optimizing bone mass and strength. The role of physical activity and nutrition during growth. Med Sport Sci Basel: Karger (vol 51), 81-101

30. Zhang H, Xie H, Zhao Q, Xie GQ, Wu XP, Liao EY, Luo XH. (2010) Relationships between serum adiponectin, apelin, leptin, resistin, visfatin levels and bone mineral density, and bone biochemical markers in post-menopausal Chinese women. J Endocrinol Invest, 33: 707-711

\section{Correspondence to:}

Rite Gruodytè-Račienè

Department of Health, Physical and Social Education

Lithuanian Academy of Physical Education

Sporto str. 6, Kaunas LT-44221

Lithuania

E-mail: r.gruodyte@lkka.lt

Tel.: +370 37302669

Fax.: +370 37204515 